\title{
Cultural aspects of meals and meal frequency
}

\author{
BY MATTY CHIVA \\ University of Paris X-Nanterre, UFR Sciences Psychologiques et Sciences de l'Education, 200 av. de la \\ République, 92001 Nanterre cedex, France
}

\begin{abstract}
The present paper presents a certain number of cultural elements which interact in the determination of the frequency of food intake. Approaches from various perspectives (historical, ethnological, anthropological, sociological) draw attention to two major aspects relating to the periodicity of food intake: the extreme cultural diversity and the continual modifications which have occurred over time and space. The various cultural models change and are subject to multiple influences, for example, cross-cultural, economic and historical. In addition, there are interactions between the models. The definitions of food intake and frequency play a major role in building up consumers' perceptions. These various perceptions are multiple (perception of self, of food and its virtues, the rules and moral values of consumption) and finally influence behaviours. Finally, and taking into account the systems of beliefs, the very nature of feeding behaviours may carry feelings of guilt for the subject. The study of real behaviours and their relationship with health is still incomplete for reasons of methodology and also of conceptual definition. In future, data collection has to take into account real behaviour as well as subjective perceptions and value judgements. $A$ specific effort has to be made in the future to develop methodology. This should allow the collection of reliable data and particularly comparisons between studies, without oversimplifying and distorting cultural specificities.
\end{abstract}

Meal frequency: Eating behaviour

Human eating behaviour depends on both biological and cultural aspects. However, usual practices relating to the nature and range of food variety, ways of preparing food, the norms of consumption and social conventions of the time or quantity of meals, are all critically dependent on cultural aspects, except, perhaps, the amount of total energy intake. In this area, one can say, with reasonable certainty, that acquired knowledge is always more important than inborn knowledge.

Historical (Flandrin \& Montanari, 1996), ethnological (de Garine, 1979; de Garine \& Harrison, 1985), anthropological (Farb \& Armelagos, 1980) and sociological (Fischler, 1990) research studies focus attention on two issues: the extreme diversity of eating habits from one culture to another and the constant transformation over time within a given culture. These changes involve, for example, eating behaviour as well as eating frequency.

Chronobiology cannot satisfactorily establish the time determinism of meal frequency. Time as well as frequency of eating are far more dependent on social and cultural factors and upon perceptual constructs about food itself than upon strictly physiological aspects. Thus, the construction of perception of food, which cannot be dissociated from the eater's self-identity (Chiva, 1996), is not merely a cognitive process. Diverse cognitive and affective learning, hedonic factors and value judgements from different models interact.

Finally, two other questions arise in this context: (a) the first relates to definitions of meals and what can be considered as a snack; (b) the second relates to the influence of these diverse types of food takings from an objective and subjective point of view. It is advisable also to question the accuracy and value of data about food intake collected using present-day methods. 
Future research will have to address these issues and, therefore, will require the development of appropriate methodologies. The essential point with regard to methods will be the use of approaches allowing, in naturalistic situations, a better knowledge of the real behaviour of individuals and of their own appreciation of these behaviours, and this must go beyond macro-economic or behavioural or even 'admitted attitudes' approaches.

\section{FOOD CONSUMPTION RHYTHMS IN TIME AND SPACE}

Western societies, in general, recommend a structured distribution of food takings: these are what are usually called 'meals'. Three is the usual number of such meals: breakfast, lunch and dinner. Their importance in terms of energy consumption varies from one meal to another and differs according to culture. So, for example, breakfast which is important in English-speaking countries, is reduced to bare essentials in Italy. The importance of breakfast can also vary according to social class and geographical situation (for example, urban or rural location). The same applies to the time of these meals, which can vary greatly from one human group to another; to quote only one example, dinner is at about 17.30 or 18.00 hours in the United States and about 22.00 hours in Spain. According to culture, one accepts or allows other food takings between meals, before or after dinner; for example, afternoon snack, light meal before sleep. Finally, in Western societies, different numbers of food takings are accepted, for example according to age. Thus, children as well as the elderly are supposed to take food between meals. The 'justifications' are different, however; in the first case, it is because of an increased requirement for energy in periods of growth; in the second case, it is because food intake is spread throughout the waking hours because of the digestive difficulties older people are thought to suffer from. Taking this diversity into account, one can ask whether historical or even prehistoric data or ethnological approaches can give information about what could be a 'natural' rhythm of food taking. (Two remarks on this point: what can 'natural' mean about humankind when every civilization has created and modelled its environment in a reciprocal adaptation of man and his environment? In asking such a question, one finds another question, which can be labelled as 'mythical', that is about the existence of a 'body wisdom' which makes the eater 'naturally' aware of what is good for him and what he needs. At present, there is no satisfactory scientific answer to this point.) The answer is necessarily full of nuances. It can be summarized in three points:

(a) From a prehistoric point of view, according to present consensus, two practices are known to have coexisted at the beginning as techniques for survival: gathering and hunting. They both refer to a precarious situation, a day-to-day search, due to the difficulty in obtaining and conserving foods. In the perspective developed here, the following two items seem to emerge:

a consumption distributed widely over time, particularly dependent on gathering. This pattern of consumption has, in other contexts, been termed 'alimentary vagabondage' (Aymard et al. 1993);

the more important role attributed to meat, not only from a nutritional point of view, but, moreover, from a symbolic point of view. The evolution from solitary hunting of small animals to the organized hunting of big game played an important part. It actually required a social organization based on cooperation for hunting and its direct implication, sharing. According to some pre-historians (Perlès, 1996), during the late Palaeolithic Age, organized hunting and sharing played a major part in organizing human groups and in the genesis of social structures. Of course, later, the advent of agriculture, at the beginning of 
the Neolithic Age, considerably modified alimentary habits. Cultivation of cereals and domestication of animals, systemized in increasingly more-structured societies, blaze the trail of our present traditional alimentation.

(b) The data from ethnological research show a complex pattern in the number and rhythm of food takings. At the very least, one can distinguish two trends: multiple, erratic, food takings as in the hunter-gatherer societies compared with the regularity and rhythmicity of harvest societies (Human Relations Area Files; a copy can be found at Collège de France, Paris, France). But even in these cases, differences are not always quite established. Thus, in many ethnic groups practising both agriculture and hunting, there is a combination of habits: produce from hunting, especially big game, is brought back home for ritual apportionment and collective consumption. But, at the same time, hunters eat on the spot some of the foods they can find as they walk around (berries, fresh caterpillars, various ants, etc.), this consumption being one of their privileges. These practices are not limited to a definite geographical area and can be found in South America as well as in a number of Pacific cultures.

Moreover, ethnological information does not allow the conclusion that customs are rigid, and unchanging with time. In traditional societies, very often, periodicity of food intake can be low, for economical reasons; thus, often, in rural African societies there are only two meals daily or even less. At the same time, and particularly at the present time, the influence of some social structures and economic constraints can be observed. As a result, traditional societies give up their traditional cultures and adopt other food habits at the risk of losing their cultural identity.

Finally, the study of societies other than Western, clearly shows the existence of twofold systems. Thus, the Chinese meal obeys very strict rules and rituals. But when economic circumstances allow it, people eat between meals, individually and without any code. Thus, Chinese people are consuming, when it is possible, at any time of the day or of the night, according to supply and demand (Aymard et al. 1993).

(c) Another important point which creates differences between human groups is religion. Considering the enormous variation from this point of view, particular attention has to be paid to religious rules defining food intake frequency and periodicity. One of the best examples is the observance of Ramadan in Muslim cultures; during this period of 1 month, Muslims cannot eat from sunrise until sunset. In other words, for 1 month food intake can take place only during the night; it is potentially possible that this situation has a chronobiological influence, being an external rhythmic reference or zeitgeber. A similar situation also exists in other religions and fasting is a quite usual custom, with different periodicities. (d) From an historical point of view, it can be established from existing data that the time and number of meals have constantly changed within occidental societies. Flandrin (1993) has shown, from a detailed study, the changing of times for meals between the years 1100 and 1808 among European societies.

In the same historical period, not only the time and the total number of meals per day changed, but also serving rules and presentation of meals. For example, until the 19th century in France meals were served by 'services'; that means that a range of various meals was presented at the same time. According to social status, the number of 'services' and the number of different meals in the same 'service' could be different. The quantity of each meal presented was less than enough for all the guests; this was an opportunity for social exchanges and the expression of complicated rules of hierarchy.

At the end of the 19th century the 'Russian service' appeared, i.e. one meal, the same for all, was served at a time. Meal taking became a succession of identical servings for all 
the people around the table, instead of a simultaneous presentation of different dishes (Aron, 1973).

The simultaneous presentation of all the dishes composing the whole meal exists still in different non-Western cultures: Middle East, India, the Far East etc. It depends also on the place where the meal is taken; at home or outside the home.

On the other hand, historical approaches, just like ethnological information put emphasis on the importance of conviviality rules for food taking. In this context, conviviality plays a part not only in socialization, in that it imposes social code, but also in social distinctions. The making up of meals, the identity of guests, their temporal aspect have been used in order to distinguish gods and their servants from mankind as well as to make a distinction later among food takings by diverse social groups (Flandrin \& Montanari, 1996). Furthermore, eating rules of some social classes were held up as an example and were imitated by other social strata. Thus, court and middle class have imitated and been imitated at various historical periods (Elias, 1973).

However, this conviviality does not exclude individual or individualized food behaviours. The latter is not desocialized and can be an integral part of the system. It remains true, however, that in the present day attitudes regarding food behaviours can be different, as we shall see.

\section{DEFINITION AND PERCEPTION OF FOOD TAKING}

The very definition of food taking sets a problem which has to be considered from a dual point of view: the scientist's and the consumer's.

Definitions proposed by scientists to differentiate meals from snacks are numerous and based on different aspects: for example, presence or absence of guests (Rotenburg, 1981), lapse of time between food takings, associated or not with energy intake of these different food takings (Bernstein et al. 1981; de Castro, 1993). These definitions are then used for diverse studies. But their diversity itself often makes the comparison between studies difficult.

The consumer himself has no precise definition for the categorization of the diverse food takings. The difficulty for the consumer in giving a definition of breakfast in France is an example; if breakfast is considered as the first meal of the day, is the cup of coffee drunk before preparing breakfast to be included in this meal or is it not? And should the cup of coffee drunk 1 hour later, on arrival at the office, with or without a cookie or a cake, still be considered as part of breakfast? Or should it be defined as food taking or a snack? A study in progress shows how these definitions remain very vague among people (M. Chiva, $S$. Lalhou and P. Weil, unpublished results).

These definitions are primarily dependent on the construction of perceptions. These perceptions are multiple, inter-related, and located at different levels. One can briefly distinguish:

(a) construction of the very concept of food 'for myself'. Actually, for every one of us, the concept of food is learnt from cultural referencing. It is from this referencing that one can select among all edible items the ones which are 'for myself' as an individual. But we have to keep in mind that this apprenticeship comes from within a cultural group which has already defined its own food referencing. So that learning food referencing, just like learning a native tongue, is a socialization process and a way to build up one's identity (Fischler, 1990).

Food intake also plays a major role in the construction of the concept of self from a different point of view. As eating is one of the possible ways to modify body shape, it plays 
a major role in the definition of the concept of beauty and sexual attractiveness. Thus, in many cultural groups, in the Middle East and Africa, for example, women are considered as beautiful and attractive when plump (Madani \& Khashoggi, 1996).

The model also exists in Western countries but with fluctuations over time. Plumpness was considered to be an attribute of beauty for a long time, before changing and giving way to leanness (Chiva \& Nahoum, 1981). In the present day one can observe shifts between the models in fashion and, as an outcome, modified food intake by women.

(b) In addition to construction of the food concept within a given social frame, there is also the construction of perception of each food itself. We now know that 'specific qualities construction' for each food depends on both cognitive and hedonic factors. Cognitive factors play a dominant role in the internalization of sensorial information, and also in the learning of norms in conformity with the group to which the individual belongs.

The hedonic factor, which constitutes a real functional specificity as far as taste is concerned, is influenced both by physiological specificity and by further social learning. Then, at the same time, there is interference from norms, from what is considered as pleasant by the group, and personal affective experiences linked to the consumption of foods (Rozin, 1984; Rigal \& Chiva, 1995; Chiva, 1996). Perception built up in this manner partakes not only of social identity construction but also of self identity construction.

(c) Belief about foods. This factor is made up of two elements: information from objective knowledge and information from belief and 'magic thought'.

Information from objective knowledge, or knowledge considered to be objective, comes from diverse origins: teaching, information from the media, personal reading, advice from experts (or people considered to be experts). In this case, it is important to take into account distortions brought about not only by individual interpretation but also by media interpretation of data from scientific research. Many of these distortions relate to moral judgements about foods and food habits (Nemeroff, 1994; Fischler, 1996). That is why some foods are considered as objectively good for health, or why snacking is 'bad', mainly because it is considered as individualistic behaviour with no social context.

'Magic thought' is a way of thinking which attributes to foods some virtues, qualities and dangers; however, justification is built up through modes of reasoning which are not derived from logical thought. Thus, for example, in France carrots are considered to make people agreeable, elsewhere eating meat makes people aggressive. Within this field of reasoning, we can also find many powers attributed to foods: aphrodisiac, giving courage, wisdom, or acquisition of specific powers. Magic thought, in this sense, is widespread in every society, and coexists with logical thought.

Thus, we have to consider diverse levels in the consumer, in food perception and in the ways of consuming food. Objective knowledge, health advice given by the media, personal beliefs and moral aspects interact, as do hedonic factors, in determining feeding behaviour.

\section{DISSONANCE BETWEEN ATTITUDES AND PRACTICES}

Direct study of human eating behaviour is sensitive and difficult. The ideal method would consist of qualitative and objective analysis of food consumption. But this is only seldom realised because it is a sensitive task which is expensive in time and money. This kind of approach is usually undertaken in two contexts: in research with volunteers in the laboratory, subjects living in an experimental environment for quite a long period (so they are outside their usual environment), or in ethnological studies conducted over long periods involving participating observation of among relatively small groups. Direct observation in naturalistic situations is also difficult because the observer has to be constantly present in 
the subject's environment and because of the modifications induced by the presence of the observer. Experimental observations of food takings in the hospital or laboratory allow the collection of reliable data relating to precise physiological factors, but do not allow a generalization of data relating to spontaneous behaviour and its consequences.

Most data on feeding habits are obtained by a recall method ( $24 \mathrm{~h}$ recall or $7 \mathrm{~d}$ recall) or by questionnaires filled in at the time. The extent of the margin of error in data obtained with these methods is known. A major source of distortion with such records can be the unconscious self-censoring of the subjects according to their beliefs about what is 'good or bad'. Real errors may then occur which are difficult to detect.

Taking these facts into account, composite methods, which are more precise, have been devised. So Poulain (1996) used a dual technique: direct observation of feeding, with a particular comparison of what was taken with what was actually consumed, interview with the subjects about the meal they had just eaten and, afterwards, thorough interviews about their beliefs and habits. The observation of 1200 French adults, employed and living in town, has been undertaken in their home as well as outside the home, in restaurants at the workplace. Two sets of data are of interest:

(a) The difference between the number of food takings admitted and the actual frequency of daily food takings. When the 'admitted norm' is three meals daily, $30 \%$ of the subjects have a total of four food takings daily, $24 \%$ have five and $13 \%$ have six food takings daily. These additional food takings mostly occur between the three traditional meals and mainly between 17.00 and 18.00 hours.

(b) Among the same subjects when questioned further, $52 \%$ considered that eating between meals is 'really bad'. Among the whole population, $81 \%$ of subjects think that eating between meals 'can be a source of problems'. But in this same population, more than $75 \%$ have four takings or more (a minority have more than nine food takings daily).

A snack outside meal time is judged as 'bad' because it is considered as an individualist activity, outside the group. And in a country like France where cuisine still plays a major role, virtues of conviviality and socialization are paramount. Thus, the subjects only account consciously for situations considered as valuable from a social point of view, even if many of the snacks are as valuable (a typical example being the cup of coffee and cookies eaten with their colleagues).

Throughout these findings we can find normative and moral judgements about eating behaviour. Social norms, group norms, adhesion to cultural values and identities result, for example, from unfavourable opinions about snacks. There appears to be inconsistency between opinions and practices. This inconsistency is quite well tolerated because it is not perceived by the subjects themselves; thus, this avoids disagreement of a cognitive dissonance. On this basis, the French example cited is only of value if compared with equivalent situations studied in different cultural groups.

For example, we can consider that an invitation to snack might be more or less well perceived and accepted according to cultural context and native models. Reasons for accepting or rejecting cannot be interpreted only according to the true benefit for health. Moral aspects, values associated with food, socialization functions of the act of eating play an important part. Finally, if we consider only Western countries, in an environment of nutritional plenty, official announcements and behaviour advice on this subject will be accepted and followed differently within the various cultural groups.

\section{CONCLUSION}

We can conclude that the frequency and quantity of food takings depend mainly on food availability and cultural models of reference. These factors are all the more important to 
take into account in order that we do not overlook generalized data relating to the effects of a particular type of food takings compared with another (for example, a small number of structured meals compared with multiple food takings but providing a similar quantity of energy).

Special efforts have to be directed towards methodology for studying actual subject behaviours and the conditions and circumstances of food takings. It appears necessary to develop more sophisticated methods allowing observations of behaviour in a naturalistic environment and for long time periods.

In addition, it is necessary to build up new methods for studying the forming of opinions and value judgements about food habits. The part played by hedonic and belief factors in the development of food perception and food habits is important. Promotion and communication about products probably has a great influence on these aspects. They have to be studied in conjunction with disease prevention and health aspects but data are sparse.

This knowledge is indispensable for the development not only of health policies but also nutritional recommendations because, for most people, values and opinions often prevail over objective scientific facts.

\section{REFERENCES}

Aron, J. P. (1973). Le Mangeur du XIXe Siècle (The 19th Century Eater). Paris: Robert Laffont.

Aymard, M., Grignon, C. \& Sabban, F. (1993). Le Temps de Manger; Alimentation, Emploi du Temps et Rythmes Sociaux (Time to Eat: Food, Time Schedules and Social Rhythms). Paris: Editions MSH-INRA.

Bernstein, I. L., Zimmerman, J. C., Czeisler, C. A. \& Weitzman, E. D. (1981). Meal patterns in 'free-running' humans. Physiology and Behaviour 27, 621-623.

Chiva, M. (1992). Aspects psychologique des conduites alimentaires (Psychological aspects of food behaviours). In Alimentation et Nutrition Humaines (Human Food and Nutrition), pp. 417-444 [H. Dupin, J. L. Cuq, M. I. Maewiak, C. Leynaud-Rouaud and A. M. Berthier, editors]. Paris: ESF.

Chiva, M. (1996). Le mangeur et le mangé: la subtile complexité d'une relation fondamentale (The eater and the eaten: the subtle complexity of a fundamental link). In Identités des Mangeurs, Images des Aliments (Identity of Eaters, Image of Food), pp. 11-30 [I. Giachetti, editor]. Paris: Polytechnica.

Chiva, M. \& Nahoum, V. (1981). "Miroir, miroir au mur, suis-je la plus belle du royaume?"' ou esthétique, alimentation et canons de beaute ('Mirror, mirror on the wall, am I the most beautiful in the kingdom?' or aesthetics, food habits and rules of beauty). Informations pour les Sciences Sociales 20, 375-387.

De Castro, J. M. (1993). Genetic influences on daily intake and meal patterns of humans. Physiology and Behavior 53, 777-782.

De Garine, I. (1979). Culture and nutrition. Communications 31, 70-90.

De Garine, I. \& Harrison, G. (1985). Coping with Uncertainty in Food Supply. London: Oxford University Press.

Elias, N. (1973). La Civilisation des Moeurs (The Civilization of Manners). Paris: Pluriel.

Farb, P. \& Armelagos, G. (1980). Anthropologie des Coutumes Alimentaires (Anthropology of Food Habits). Paris: Denoël.

Fischler, C. (1990). L'Homnivore (The Omnivore). Paris: O. Jacob.

Fischler, C. (1996). Alimentation, morale et société (Food, morals and society). In Identité des Mangeurs, Images des Aliments (Identity of Eaters, Image of Food), pp. 31-24 [I. Giachetti, editor]. Paris: Polytechnica.

Flandrin, J. L. (1993). Heures des repas entre 1100 et 1808 (Meal times from 1100 to 1808). In Le Temps de Manger; Alimentation, Emploi du Temps et Rythmes Sociaux (Time to Eat: Food, Time Schedules and Social Rhythms), [M. Aymard, C. Grignon and F. Sabban, editors]. Paris: Editions MSH-INRA.

Flandrin, J. L. \& Montanari, M. (editors) (1996). Histoire de l'Alimentation (A History of Food). Paris: Fayard.

Madani, K. A. \& Khashoggi, R. H. (1996). The affluent dietary diseases in Saudi Arabia in Diet-related Noncommunicable Diseases in the Arab Countries of the Gulf, pp. 83-98 [A. O. Musaiger and S. S. Miladi, editors]. Cairo: FAO RNEA.

Nemeroff, C. (1994). Tabous Américains (American taboos). In Manger Magique (Magic Eating), pp. 38-50 [C. Fischler, editor]. Paris: Autrement.

Perlès, C. (1996). Les stratégies alimentaires dans les temps préhistoriques (Food strategies in prehistoric eras). In Histoire de l'Alimentation (A History of Food), pp. $29-46$ (J. L. Flandrin and M. Montanari, editors]. Paris: Fayard.

Poulain, J. P. (1996). La modernité alimentaire; entre commensalité et vagabondage (Food modernity, between conviviality and 'alimentary vagabondage'). Ethnologie Française (In the Press).

Rigal, N. \& Chiva, M. (1995). Modelage culturel des préférences alimentaires chez l'enfant (Cultural modelling of food preferences in the child). Revue de Nutrition Pratique 8, 7-11. 
Rotenburg, R. (1981). The impact of industrialisation on meal patterns in Vienna, Austria. Ecology of Food and Nutrition 11, 25-35.

Rozin, P. (1984). The acquisition of food habits and preferences. In Behavioural Health: A Handbook of Health Enhancement and Disease Prevention, pp. 590-607 [J. D. Matarazzo et al., editors]. New York: Wiley \& Son.

Rozin, P. \& Fallon, A. (1980). The psychological categorisation of foods and non foods: a preliminary taxonomy of food rejections. Appetite 1, 193-201. 